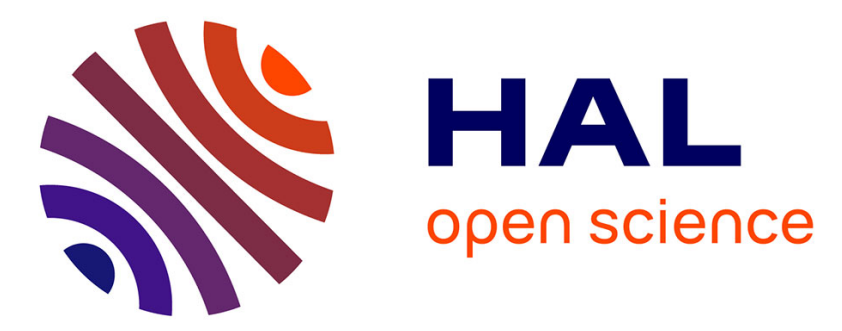

\title{
Point-of-care creatinine testing in patients receiving contrast-enhanced computed tomography scan
}

Anne-Sophie Bargnoux, Olivier Beaufils, Maryse Oguike, Aurélie Lopasso, Anne-Marie Dupuy, Mustapha Sebbane, Stéphanie Badiou, Pierre Fesler, Jean-Paul Cristol

\section{To cite this version:}

Anne-Sophie Bargnoux, Olivier Beaufils, Maryse Oguike, Aurélie Lopasso, Anne-Marie Dupuy, et al.. Point-of-care creatinine testing in patients receiving contrast-enhanced computed tomography scan. Clinica Chimica Acta, 2018, 478, pp.111 - 113. 10.1016/j.cca.2017.12.025 . hal-01738263

\section{HAL Id: hal-01738263 \\ https://hal.umontpellier.fr/hal-01738263}

Submitted on 7 Jan 2020

HAL is a multi-disciplinary open access archive for the deposit and dissemination of scientific research documents, whether they are published or not. The documents may come from teaching and research institutions in France or abroad, or from public or private research centers.
L'archive ouverte pluridisciplinaire HAL, est destinée au dépôt et à la diffusion de documents scientifiques de niveau recherche, publiés ou non, émanant des établissements d'enseignement et de recherche français ou étrangers, des laboratoires publics ou privés. 


\title{
Point-of-care creatinine testing in patients receiving contrast-enhanced computed tomography scan
}

\author{
Anne-Sophie Bargnoux ${ }^{\mathrm{a}}$, Olivier Beaufils ${ }^{\mathrm{b}}$, Maryse Oguike ${ }^{\mathrm{b}}$, Aurélie Lopasso ${ }^{\mathrm{c}}$, \\ Anne-Marie Dupuy ${ }^{\mathrm{c}}$, Mustapha Sebbane ${ }^{\mathrm{d}}$, Stéphanie Badiou ${ }^{\mathrm{a}}$, Pierre Fesler ${ }^{\mathrm{e}}$, Jean-Paul Cristol ${ }^{\mathrm{a}, *}$ \\ ${ }^{a}$ Laboratoire de Biochimie, CHU de Montpellier, PhyMedExp, University of Montpellier, INSERM U1046, CNRS UMR 9214,34295 Montpellier Cedex 5, France \\ ${ }^{\mathrm{b}}$ Service des Urgences Têtes et Cou, CHU Montpellier, Univ Montpellier 1, Montpellier F-34000, France \\ ${ }^{\mathrm{c}}$ Laboratoire de Biochimie, CHU Montpellier, Univ Montpellier 1, Montpellier F-34000, France \\ ${ }^{\mathrm{d}}$ Service des Urgences, CHU Montpellier, Univ Montpellier 1, Montpellier F-34000, France \\ e Service de Médecine Interne, CHU Montpellier, Univ Montpellier 1, Montpellier F-34000, France
}

Keywords:

Creatinine

Point-of-care testing

Contrast-enhanced computed tomographyscans

Emergency department

\begin{abstract}
A B S T R A C T
Background: The aim of this study was to evaluate the creatinine assay on the ABL800 FLEX@ blood gas analyzer for the screening of pre-existing renal impairment before radiographic contrast administration in the emergency department (ED), by comparing it with standard practice using central laboratory blood testing.

Methods: The evaluation comprised two elements. The first, conducted in the central laboratory, focused on the analytical performance of the ABL800 creatinine assay. This included assessment of imprecision and accuracy by comparison with central laboratory standard creatinine assay. We also compared ABL 800 estimated glomerular filtration rate (eGFR) and ${ }^{99 \mathrm{~m}}$ Tc-DTPA measured GFR (mGFR). The second part, conducted in ED sought to determine the impact that implementation of the creatinine at the point-of-care (POC) has on the timeframe in which ED patients are submitted for computed tomography scan (CT).

Results: The ABL800 enzymatic creatinine assay met the National Kidney Disease Education Program acceptance criteria for imprecision and showed good agreement with the isotope dilution mass spectrometry-traceable Roche enzymatic assay used in the central laboratory. Furthermore, ABL800 eGFR was in total agreement with mGFR by a reference method. The implementation of POC testing creatinine in the ED significantly reduced patient waiting times for contrast enhanced CT (1.73[0.75-3.01] vs 2.57 [1.53-3.48] hours, for period with and without ABL800 respectively, $p=0.04$ ).

Conclusion: The ABL800 assay is comparable with central laboratory reference method in terms of analytical performance and superior in terms of turnaround time. Implementation of creatinine at POC reduces delay results, potentially allowing ED clinical staff to make more rapid clinical decisions and reduce patient waiting time.
\end{abstract}

\section{Introduction}

Improving emergency department (ED) patient flow is of particular importance to reduce overcrowding. Point-of-care testing (POCT) in ED reduces turnaround time (TAT) for results compared with central laboratory testing [1-3]. Reduced TAT could reduce time to disposition decision [4-6] and patient journey time [7]. POCT allows creatinine results to be available in $30 \mathrm{~s}$ to $5 \mathrm{~min}$ [8] and thereby, assessment of renal function by emergency room clinical staff immediately prior to scheduled procedures such as contrast enhanced computed tomography (CT) examination. This is highly relevant because assessment of renal function before contrast enhanced computed tomography scan is essential for patient safety. Exposure of patients with reduced renal function to contrast media increases the risk of an acute kidney injury (AKI) known as contrast-induced nephropathy (CIN) $[9,10]$.

The aim of this study was to evaluate the ABL800 FLEX@ blood gas analyzer (ABL800) (Radiometer Medical ApS, Copenhagen, Denmark) for creatinine determination at the POC. We assessed imprecision, comparison of the ABL800 to a laboratory standard, comparison of ABL 800 eGFR to ${ }^{99 \mathrm{~m}} \mathrm{Tc}$-DTPA measured GFR (mGFR) and the patient processing time after implementation of the ABL800 at the POC in the Head and Neck ED.

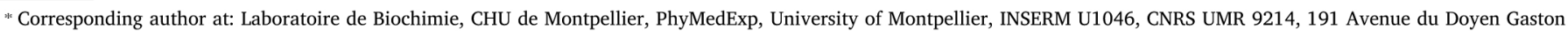
Giraud, 34295 Montpellier Cedex 5, France.

E-mail address: jp-cristol@chu-montpellier.fr (J.-P. Cristol).
} 


\section{Materials and methods}

\subsection{Study design}

Analytical evaluation of creatinine on the ABL800 was performed in the central laboratory. Creatinine on the ABL800 is determined by an isotope dilution mass spectrometry (IDMS)-traceable enzymatic method based on the amperometric measurement of oxygen [8,11]. After ED nurse training and certification, ABL800 creatinine testing by nurses was implemented in the Head and Neck ED to investigate how the creatinine at the POC impacts on waiting time of ED patients. The study was conducted according to the principles of the Declaration of Helsinki.

\subsection{Verification of the $A B L 800$ creatinine analytical performance in the central lab}

Samples to estimate imprecision were prepared using 6 heparinized whole blood and 6 plasma pools. Within-day imprecision was determined by 15 replicated analyses. Between-day imprecision on whole blood samples was assessed on $\mathbf{5}$ consecutive days, with 3 determinations per day ( $n=15$ replicates) by repeat analysis of the same pools stored at $4{ }^{\circ} \mathrm{C}$. Between-days imprecision on plasma pools was assessed on 10 consecutive days, with 3 determinations per day $(n=30$ replicates) by repeat analysis of the same pools divided into aliquots stored at $-20{ }^{\circ} \mathrm{C}$.

ABL800 creatinine results were compared with those obtained using the Roche enzymatic IDMS traceable creatinine assay (c701/cobas 8000 analyzer), which closely correlates with a gas chromatography IDMS method $[12,13]$. Clinical concordance was assessed by comparison of eGFR, as reported with the ABL800 creatinine result, with the mGFR by a reference isotopic method. This involves measurement of urinary clearance of technetium-labeled diethylene-triamino-pentaacetic $\left({ }^{99 \mathrm{~m}}\right.$ Tc-DTPA) using the constant infusion technique [14]. A total of 55 patients (33 men, 22 women, $54.0 \pm 14.1$ years) from the outpatient clinic of the Department of internal medicine who came for renal monitoring entered this study.

\subsection{Evaluation of POCT implementation in the emergency department}

Patients, with acute symptoms suggestive of stroke admitted to ED and needing contrast enhanced brain and/or neck angio-CT were enrolled in this study. In phase 1 ( 6.5 weeks, $n=51$ ), POCT was not implemented in the ED and patient management decisions were made based on central laboratory creatinine results. In phase 2 (5.5 weeks, $n=67$ ), POCT was implemented in the ED and patient management decisions were made on POCT creatinine results generated by certified nurse analysis. The primary outcome measure was the interval from a patient's arrival at the ED to CT examinations. We also recorded the interval from a patient arrival at the ED to the reporting of central laboratory results in phase 1 and reporting of POCT results in phase 2 .

\subsection{Statistical analysis}

Linear regression analysis was performed to compare data from the two methods used for creatinine determination and the scatter of differences was visualized according to the Bland-Altman representation [15]. Mann-Whitney test was used to compare time before CT examination between the 2 periods. Values were considered statistically significant at $p<0.05$.

\section{Results}

\subsection{Verification of the ABL800 creatinine performance}

Imprecision profiles are shown in Table 1 . Based on the National
Table 1

Summary of imprecision data of ABL800 creatinine assay on whole blood and plasma pools samples.

\begin{tabular}{|c|c|c|c|c|}
\hline \multirow[t]{2}{*}{ Samples } & \multicolumn{2}{|c|}{ Whole blood pools } & \multicolumn{2}{|c|}{ Plasma pools } \\
\hline & $\begin{array}{l}\text { Mean } \\
(\mu \mathrm{mol} / \mathrm{L})\end{array}$ & $\begin{array}{l}\text { CV } \\
(\%)\end{array}$ & $\begin{array}{l}\text { Mean } \\
(\mu \mathrm{mol} / \mathrm{L})\end{array}$ & $\begin{array}{l}\text { CV } \\
(\%)\end{array}$ \\
\hline \multicolumn{5}{|c|}{ Within day imprecision } \\
\hline Pool 1 & 47.2 & 3.8 & 57.3 & 3.0 \\
\hline Pool 2 & 92.3 & 2.6 & 110.0 & 2.6 \\
\hline Pool 3 & 220.1 & 1.7 & 209.5 & 1.2 \\
\hline \multicolumn{5}{|c|}{ Between-days imprecision } \\
\hline Pool 1 & 51.3 & 3.7 & 49.5 & 2.6 \\
\hline Pool 2 & 102.3 & 3.6 & 93.3 & 2.0 \\
\hline Pool 3 & 232.6 & 3.5 & 222.4 & 1.9 \\
\hline
\end{tabular}

Kidney Disease Education Program (NKDEP) criteria [16], the Radiometer ABL800 creatinine method reaches the desirable specifications $(2.2 \%)$ for creatinine values higher than $90 \mu \mathrm{mol} / \mathrm{L}$ and the minimum specification $(3.2 \%)$ for creatinine values at $50 \mu \mathrm{mol} / \mathrm{L}$. The slightly higher coefficients of variation found on whole blood pools could be explained by the deterioration over the five days at $4{ }^{\circ} \mathrm{C}$. For the comparison study, we analyzed 178 samples, concentration range, 23 to $1597 \mu \mathrm{mol} / \mathrm{L}$ with Roche enzymatic assay. The following linear regression equation was obtained: ABL800 creatinine $=1.0$ Roche enzymatic creatinine - $1.2(r=0.94)$. The mean and limits of agreement (mean \pm 1.96 standard deviation) of the difference according to Bland-Altman's study between enzymatic creatinine on c701/Cobas 8000 and ABL800 was $0.4 \pm 26.7 \mu \mathrm{mol} / \mathrm{L}$ (Fig. 1 ). The mean mGFR using ${ }^{99 \mathrm{~m}} \mathrm{TcDTPA}$ was $81.7 \pm 36.2 \mathrm{~mL} / \mathrm{min} / 1.73 \mathrm{~m}^{2}$. Since an eGFR value $<60 \mathrm{~mL} / \mathrm{min} / 1.73 \mathrm{~m}^{2}$ was traditionally used to define patients at risk of developing contrast induced kidney dysfunction $[3,16]$, we analyzed the concordance according to this cut-off value. All patients $(n=17)$ having a mGFR $<60 \mathrm{~mL} / \mathrm{min} / 1.73 \mathrm{~m}^{2}$ were classified as CKD stage 3 using the ABL800 eGFR.

\subsection{Evaluation of POCT implementation in the emergency department}

During phase 1, central lab creatinine results were available in 1.95 [1.68-2.48] hours (med [IQR]). During phase 2, the median time to obtain creatinine result after patient arrival was found to be 0.52 [0.23-1.13] hours (med [IQR]) with POCT $(p<0.001$, versus central lab result). Transport from clinical department to central lab (1.12

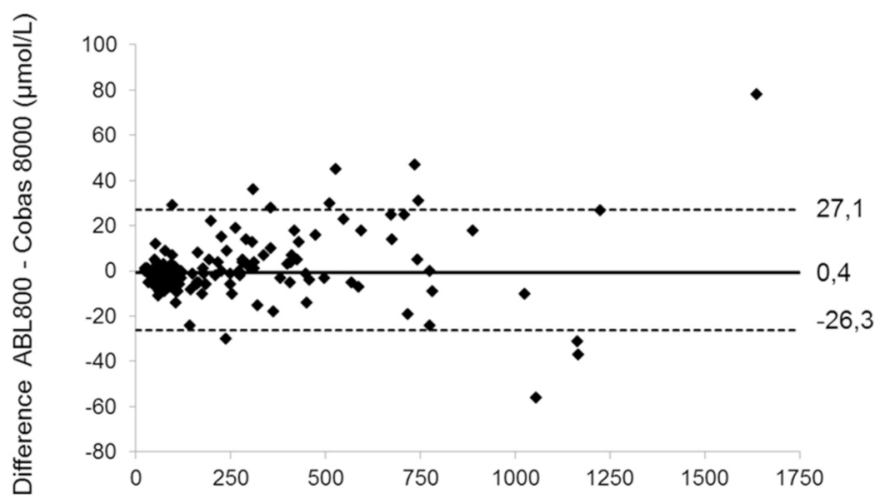

Average ABL800 and Cobas 8000 ( $\mu \mathrm{mol} / \mathrm{L})$

Fig. 1. Bland-Altman plot representation ( $n=178$ samples) for enzymatic creatinine on c701/Cobas 8000 (plasma) and ABL800 (whole blood). The difference between two values in the $\mathrm{y}$ axis is plotted against the average of the two measurements in the $\mathrm{x}$ axis. The solid horizontal line represents the mean difference in measured creatinine concentration between the methods, and the dashed lines represent 95\% limits of agreement (mean of difference \pm 1.96 standard deviation). 
[0.75-1.84] hour), and centrifugation followed by analyzer turnaround time after arrival in the laboratory (0.83 [0.74-0.97] hour), contributed to the observed difference. The implementation of POCT creatinine in the ED significantly reduced patient waiting times for contrast enhanced CT (1.73[0.75-3.01] vs 2.57 [1.53-3.48] hours, for period with and without ABL800 respectively, $p=0.04$ ).

\section{Discussion}

In this study, we first validated the ABL800 device for creatinine measurement in our central laboratory. The performances and diagnostic accuracy of the assay were found acceptable at the clinical level. The ABL800 enzymatic creatinine met the NKDEP acceptance criteria for imprecision and presented good agreement with the IDMS- traceable Roche enzymatic assay with a small bias $<2 \%$. These results are in total agreement with two previous studies $[11,17]$. In addition, the use of ABL800 creatinine is appropriate for estimation of GFR and detection of renal function deterioration at the critical value of $60 \mathrm{~mL} / \mathrm{min} /$ $1.73 \mathrm{~m}^{2}$.

Secondly, we implemented the device in ED to assess the potential improvement in waiting times for contrast-induced CT examination. Previous studies addressing the impact of POCT on flow processing in ED have given conflicting results $[1,2]$. A few of these studies have addressed the particular use of POC creatinine devices for detecting patients at risk of CIN $[5,6,18]$. In accord with all these studies, we found POC creatinine measurement to be associated with a significant reduction in the time to receipt of test results. This shorter response time could potentially reduce patient waiting time. In their study, Nichols et al. [5] found that use of POCT significantly decreased the mean waiting times from arrival to elective invasive cardiac and radiologic procedures for patients who needed renal testing $(141 \pm 52$ vs $188 \pm 52 \mathrm{~min}$, for phase with and without POCT respectively, $p=0.02$ ). Similarly, we found that contrast induced CT examination was performed about $50 \mathrm{~min}$ earlier with the implementation of ABL800. These benefits could optimize patient management and outcome.

We acknowledge some limitations of our study. First, this is a monocentric study performed in the context of contrast induced CTscan, where creatinine is of particular importance to estimate GFR. Therefore, it may not be generalizable to other hospitals with different organization. Second, aspects of the ABL800 do not make it an ideal point of care analyzer. It has a larger footprint than most POC analyzers, and requires substantial maintenance and trouble-shooting compared to a typical POC device that employs disposable analytical components. The ABL800 is better suited for the hospital or satellite laboratory environment [8]. In our study, maintenance and troubleshooting were performed by a dedicated POCT team based in the central laboratory. It should be noted however that creatinine is now available (since 2017) on the ABL90 FLEX PLUS analyzer, a much more compact blood gas analyzer, better suited for POCT. Third, precision and accuracy studies were only performed by laboratory personnel at the central laboratory and not by end users (nurses) in the ED, stressing the importance of a rigorous training before ED staff empowerment. Finally, design of the study did not allow us to investigate the medicoeconomic aspect of POCT implementation. The cost effectiveness of creatinine POCT is difficult to calculate because of the many factors involved including not only reagent costs, but also the impact on workflow and medical care of the patients [6].

In conclusion, we have demonstrated that a rapid kidney function assessment at the POC improve waiting times before CT examination in an ED. In addition, the ABL800 meets expectations of physicians and nurses by: reducing delay of results in real time, low blood volume requirement, and allowing the potential for more rapid clinical decision-making.

\section{Conflict of interest}

None

\section{Acknowledgments}

Reagents for the ABL800 Creatinine assay used in this study were kindly provided by Radiometer France.

\section{References}

[1] S. Oredsson, H. Jonsson, J. Rognes, L. Lind, K.E. Göransson, A. Ehrenberg, K. Asplund, M. Castrén, N. Farrohknia, A systematic review of triage-related in terventions to improve patient flow in emergency departments, Scand. J. Trauma Resusc. Emerg. Med. 19 (2011) 43.

[2] P.R. Jarvis, Improving emergency department patient flow, Clin. Exp. Emerg. Med. 3 (2016) 63-68.

[3] F. Martínez Lomakin, C. Tobar, Accuracy of point-of-care serum creatinine devices for detecting patients at risk of contrast-induced nephropathy: a critical overview, Crit. Rev. Clin. Lab. Sci. 51 (2014) 332-343.

[4] S.E. Asha, A.C. Chan, E. Walter, P.J. Kelly, R.L. Morton, A. Ajami, R.D. Wilson, D. Honneyman, Impact from point-of-care devices on emergency department patient processing times compared with central laboratory testing of blood samples: a randomized controlled trial and cost-effectiveness analysis, Emerg. Med. J. 31 (2014) 714-719.

[5] J.H. Nichols, T.S. Kickler, K.L. Dyer, S.K. Humbertson, P.C. Cooper, W.L. Maughan, D.G. Oechsle, Clinical outcomes of point-of-care testing in the interventional radiology and invasive cardiology setting, Clin. Chem. 46 (2000) 543-550.

[6] E. Lee-Lewandrowski, C. Chang, K. Gregory, K. Lewandrowski, Evaluation of rapid point-of-care creatinine testing in the radiology service of a large academic medical center: impact on clinical operations and patient disposition, Clin. Chim. Acta 413 (2012) 88-92.

[7] P. Jarvis, T. Davies, K. Mitchell, I. Taylor, M. Baker, Does rapid assessment shorten the amount of time patients spend in the emergency department? Br. J. Hosp. Med. (Lond) 75 (2014) 648-651.

[8] M.D. Shephard, Point-of-care testing and creatinine measurement, Clin. Biochem. Rev. 32 (2011) 109-114.

[9] P. Parfrey, The clinical epidemiology of contrast-induced nephropathy, Cardiovasc. Intervent. Radiol. 28 (2005) S3-11.

[10] J.S. McDonald, R.J. McDonald, R.E. Carter, R.W. Katzberg, D.F. Kallmes, E.E. Williamson, Risk of intravenous contrast material-mediated acute kidney injury: a propensity score-matched study stratified by baseline-estimated glomerular filtration rate, Radiology 271 (2014) 65-73.

[11] A. Skurup, T. Kristensen, G. Wennecke, National Kidney Disease Education Program Laboratory Working Group, new creatinine sensor for point-of-care testing of creatinine meets the National Kidney Disease Education Program guidelines, Clin. Chem. Lab. Med. 462 (2008) 3-8.

[12] L. Piéroni, P. Delanaye, A. Boutten, A.S. Bargnoux, E. Rozet, V. Delatour M.C. Carlier, A.M. Hanser, E. Cavalier, M. Froissart, J.P. Cristol, Société Française de Biologie Clinique, A multicentric evaluation of IDMS-traceable creatinine enzymatic assays, Clin. Chim. Acta 412 (2011) 2070-2075.

[13] N. Kuster, J.P. Cristol, E. Cavalier, A.S. Bargnoux, J.M. Halimi, M. Froissart, L. Piéroni, P. Delanaye, Société Française de Biologie Clinique, Enzymatic creatinine assays allow estimation of glomerular filtration rate in stages 1 and 2 chronic kidney disease using CKD-EPI equation, Clin. Chim. Acta 428 (2014) 89-95.

[14] P. Fesler, M.E. Safar, G. du Cailar, J. Ribstein, A. Mimran, Pulse pressure is an independent determinant of renal function decline during treatment of essential hypertension, J. Hypertens. 25 (2007) 1915-1920.

[15] J.M. Bland, D.G. Altman, Measuring agreement in method comparison studies, Stat. Methods Med. Res. 8 (1999) 135-160.

[16] G.L. Myers, W.G. Miller, J. Coresh, J. Fleming, N. Greenberg, T. Greene, T. Hostetter, A.S. Levey, M. Panteghini, M. Welch, J.H. Eckfeldt, National Kidney Disease Education Program Laboratory Working Group, recommendations for im proving serum creatinine measurement: a report from the Laboratory Working Group of the National Kidney Disease Education Program, Clin. Chem. 52 (2006) $5-18$.

[17] N.L. Korpi-Steiner, E.E. Williamson, B.S. Karon, Comparison of three whole blood creatinine methods for estimation of glomerular filtration rate before radiographic contrast administration, Am. J. Clin. Pathol. 132 (2009) 920-926.

[18] J.S. You, Y.E. Chung, J.W. Park, W. Lee, H.J. Lee, T.N. Chung, S.P. Chung, I. Park, S. Kim, The usefulness of rapid point-of-care creatinine testing for the prevention of contrast-induced nephropathy in the emergency department, Emerg. Med. J. 30 (2013) 555-558. 